Salud y Tecnología Veterinaria, 3(1), 28-30

\title{
Identificación de parásitos gastrointestinales en pelicanos hallados durante una catástrofe ecológica en las costas de Lima, Perú
}

\author{
Serrano-Martínez Enrique ${ }^{1, *}$ Quispe Marco ${ }^{1}$, Andrade Roy $^{1}$, Casas Gina $^{1}$, Tantalean Manuel ${ }^{1}$ \\ ${ }^{1}$ Grupo SALUVET-UPCH. Facultad de Medicina Veterinaria y Zootecnia, Universidad Peruana Cayetano Heredia, Lima-Perú \\ * enrique.serrano@upch.pe
}

\section{RESUMEN}

En el mes de mayo de 2012, el Perú registró una inexplicable mortalidad de especies de pelícanos y delfines. Un aproximado de 5000 pelícanos y 877 delfines entre moribundos y muertos, fueron encontrados en la costa peruana, atribuyéndosele a este episodio como el "efecto pelícano"; sin embargo, la causa del fenómeno ocurrido fue atribuido a diversos factores, como los medioambientales, a patógenos virales, a factores alimenticios y a la mano del hombre, entre otros, no llegándose a esclarecer el motivo real de la mortalidad de dichas especies. En tal sentido y con la finalidad de determinar la presencia de especies parasitarias en los animales afectados, se recolectaron 07 pelicanos (Pelecanus thagus) adultos muertos y en estado conservados ó con pocas horas de descomposición en las playas (Conchan-Campomar, Venecia y San Pedro) ubicadas en el litoral del Departamento de Lima, reportando la presencia de parásitos en el 100\% de los pelícanos examinados. Especies de trematodos (Galactosomum puffini), cestodos (Tetrabothrius erostis), nematodos (Contracaecum spiculigerum) y acantocéfalos (Corynosoma sp.) fueron aislados en tejidos del tracto respiratorio y gastrointestinal de los pelicanos, siendo la especie más frecuente el T. erostis.

\section{Identification of gastrointestinal parasites in pelicans found during the ecological disaster on the coast of Lima, Peru}

\begin{abstract}
In May 2012, Peru reported an unexplained mortality of species of pelicans and dolphins. An estimated 5,000 pelicans and 877 between dying and dead dolphins were found in the Peruvian coast, attributing this episode as the "pelican effect", but the cause of the phenomenon occurred was attributed to several factors, such as environmental, to viral agent, dietary factors and the hand of man, among others, not getting itself to clarify the real cause of mortality of these species. In this regard and in order to determine the presence of parasitic species in affected animals were collected 07 pelicans (Pelecanus thagus) adults adults dead and been preserved or with few hours of decomposition on the beaches (Conchan-Campomar, Venice and San Pedro) located on the coast of Lima, reporting the presence of parasites in 100\% of the pelicans examined. Species of trematodes (Galactosomum puffini), cestodes (Tetrabothrius erostis), nematodes (Contracaecum spiculigerum) and acantocefala (Corynosoma sp.) were isolated in respiratory and gastrointestinal tract, being the most common species $\mathrm{T}$. erostis.
\end{abstract}

\section{INTRODUCCIÓN}

El Pelícano Peruano es un ave que habita a lo largo de las costas del Pacífico en Perú y Chile. Es la tercera ave guanera más importante, con una población estimada en 400,000 individuos. Se alimenta de peces que captura mientras nada o se zambulle tras de ellos, mostrando preferencia por las anchovetas y lisas. Cuando ocurre el fenómeno del Niño la población de pelícanos se reduce considerablemente al faltarle el alimento.

Durante el periodo comprendido entre febrero y mayo de 2012, se registró en el litoral peruano la muerte de al menos 5000 pelícanos y 877 delfines. En este periodo, el gobierno peruano con la mayor flota pesquera del mundo, fue víctima del "efecto 
pelícano“ trayendo como consecuencia una alerta sanitaria con la cual el consumo humano de pescado bajó en un $30 \%$ por falta de conocimiento oportuno de la causa real que ocasionó la muerte de los pelicanos; sin embargo a la fecha, la causa de la mortalidad de estas especies no fue detectada, por tal motivo el objetivo del presente estudio fue determinar la presencia de especies parasitarias en la especie Pelecanus thagus afectada por la mortalidad registrada en las costas del Perú durante el año 2012.

\section{MATERIALES Y METODOS}

Durante el período comprendido entre el 10 al 23 de Mayo de 2012, entre las 5:00 y 6:30 horas fueron colectados 07 pelícanos (Pelecanus thagus) adultos, en estado moribundo o con alguna señal de enfermedad, provenientes de las playas (ConchanCampomar, Venecia y San Pedro) del litoral del Departamento de Lima, ubicados entre el kilómetro 21 y 29.5 de la carretera Panamericana Sur. La talla y peso promedio de los pelicanos varió desde los 65 a $70 \mathrm{~cm}$ y de 6,67 a 7,32 gr, respectivamente.

Los pelicanos muestreados fueron trasladados en cajas térmicas refrigeradas al Laboratorio de Parasitología de la Facultad de Medicina Veterinaria y Zootecnia de la Universidad Peruana Cayetano Heredia, en donde fueron analizados. El procedimiento de toma de muestras de contenido y tejidos se realizó siguiendo la Técnica de Travassos (Tantaleán, 2010).

La identificación de los helmintos se basó en el análisis de los ejemplares adultos. Los parásitos obtenidos se separaron por grupo taxonómico y se lavaron con solución fisiológica; seguidamente los nemátodos se fijaron en alcohol de $70 \%$ caliente y los trematodos se colocaron, un grupo entre láminas portaobjetos y el otro en formol al 10\%. Este último grupo se usó para realizar cortes a mano con el fin de estudiar la distribución espacial de los órganos internos. La identificación de nematodos fue realizada mediante su clarificación en una mezcla de alcohol-fenol y los tremátodos se colorearon con carmín acético de Semichon de acuerdo a las técnicas convencionales.

Para la identificación genérica o específica, se compararon las características morfológicas, anatómicas y mensurables de los especímenes hallados con aquellas indicadas en la bibliografía especializada, principalmente la de Travassos et al. (1969) y Jones et al. (2005) para los tremátodos y Vicente et al. (1995) para los nemátodos.

\section{RESULTADOS}

La frecuencia de infección parasitaria en los pelicanos fue del 100\% $(n=07)$, siendo aislados una especie de nemátodo (Contracaecum spiculigerum), una especie de cestodo (Tetrabothrius erostis), una especie de tremátodo (Galactosomum puffini) y una de acantocéfalo (Corynosoma sp.) (Figura 1). La carga parasitaria promedio por animal fue de 1052 G. puffini, 1738 T. erostis, 308 C. spiculigerum y 1 Corynosoma sp.

Delasespecieshalladas, el trematodoGalactosomum puffini es el primer reporte en Perú, siendo también reportada en Panamá por Caballero et al., (1953) y Hutton y Sogandares-Bernal (1960), mientras que el género Corynosoma sp. ha sido reportado en P. thagus de Florida por Courtney y Forrester (1974).

El cestodo Tetrabothrius erostis cuyo género ha sido reportado en P. thagus de Florida y Luisiana Courtney y Forrester (1974), también ha sido reportado en el estuario del río Valdivia por Torres et al. (1982), siendo la especie que se registró con mayor carga parasitaria en la especie estudiada.

Por otro lado, el nematodo Contracaecum sp. ha sido reportado en Chile en P. thagus capturados en el estuario del río Valdivia (Torres et al., 1982). La especie Contracaecum spiculigerum (C. rudolphi) ha sido también reportada en pelícanos en Puerto Rico (Bunkley-Williams \& Williams, 1994), siendo una especie patógena que causa hemorragias graves y úlceras por la penetración del parásito en la mucosa del proventrículo del ave (Huizinga, 1971) por lo que su hallazgo muestra los daños que este parásito podría estar ocasionando a la especie P. thagus.

El presente estudio muestra la necesidad de continuar la vigilancia sanitaria de las especies afectadas en el año 2012, mediante monitoreos constantes y análisis de laboratorio, con la finalidad de establecer las verdaderas causas de la mortalidad 
de dichas especies y establecer programas sanitarios preventivos.

\section{LITERATURA CITADA}

Caballero y CE, Grocott RG, Zerecero YD. 1953. Helmintos de la Republica de Panama. IX. Algunos trematodes de aves marinas del Océano Pacifico del Norte. Annals del Instituto de Biología, Zoología, Universidad Nacional Autónoma de México 24: 391-414.

Courtney CH, Forrester DJ. 1974. Helminth parasites of the brown pelican in Florida and Louisiana. Journal of the Helminthological Society of Washington 41: 89-93.

Huizinga HW. 1971. Contracaeciasis in pelecaniform birds. Journal of Wildlife Diseases 7: 198-204.

Hutton RF, Sogandares-Bernal F. 1960. Studies on helminth parasites from the coast of Florida. II. Digenetic trematodes from shore birds of the west coast of Florida. I. Bulletin of Marine Science of the Gulf and Caribbean 10: 40-54.

Jones A, Bray RA, Gibson DI. 2005. Keys to the Trematoda. Vol. 2. CABI Publishing and The Natural History Museum. London UK. 745 p.

Torres P, Figueroa L, Saldivia A, Barrientos J. 1982. Gastrointestinal heminths of fish-eating birds from the Valdivia River, Chile. Journal parasitology 68: 1157.

Travassos LJ, Teixeira FF, Kohn A. 1969. Trematódeos do Brasil. Memórias do Instituto Oswaldo Cruz. Tomo 67. fascículo único. 886 p.

Vicente JJ, Rodrigues OH, Gomes CD, Pinto MR. 1995. Nematóides do Brasil. Parte IV: Nematóides de Aves. Revta. Bras. Zool. 12 (supl 1): 1-273 